\title{
Faculty-Study Groups Support School Improvement Efforts
}

Ann Hilliard, Bowie State University, USA

\begin{abstract}
This article focuses on effective professional interactions of teachers and administrators as faculty-study groups in school improvement practices and educational reform to improve instruction and learning. The emphasis on practical approach promises to create conditions for continuous systemic change and academic improvement. The author incorporated current knowledge of effective practices and innovative strategies into the faculty-study groups to improve teaching, learning, collaboration, and meet high academic standards. In faculty-study groups, research-based best practices for teaching excellence and learning, in addition to continuous focus on effective collaborative group efforts on "data use" in the decision making process for school improvement are shared among members and colleagues. Working together allows faculty-study groups to examine formative and summative students' data reports and to determine priority agenda goals. Coming together as a focused study group, faculty members collaboratively identify students that are at risk of meeting standards on state assessment tests. The study groups seek ways to implement appropriate intervention strategies or accommodations in their plan to meet the individual needs of students. Not only these, faculty-study groups are able to prepare, revise and/or establish new goals for the school improvement plan and develop an implementation and evaluation rubric for the plan. Moreover, the groups assist the school improvement leadership team to promote school improvement practices throughout the school. Creating a culture of accountability, showcasing success stories, providing a monthly update to the School Improvement Leadership Team (SILT), and evaluating the faculty improvement plan on the goals set forth, is another role performed by the faculty-study group. This article offers several views on how the responsibilities of faculty-study groups are identified and implemented in two middle school environments in a large school district on the east coast of the United States of America. A survey distributed to thirty-two participating members of each group provides insight on how the study groups feel about their role in school improvement. The expected outcomes of the facultystudy group are to improve the skills and practices of all faculty members, continuous participation in professional development efforts, and show how study groups can make a positive impact on school improvement and student achievement.
\end{abstract}

Keywords: Faculty-Study Groups, Formative and Summative Assessment, Priority Agenda, Culture of Accountability

\section{FACULTY STUDY GROUPS}

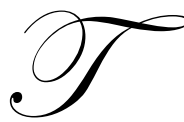

here are many definitions to describe faculty-study groups. Faculty-study groups are commonly defined as a group of five to six individuals such as teachers, specialist and school aides collaboratively working together to improve student achievement. For this review, the faculty-study groups are composed of educators within a particular school(s). Faculty-study groups meet at the same school weekly to discuss an agreed-upon topic(s). These groups put their heads together to examine formative and summative assessment data regarding students' performance and come up with practical solutions to improve student achievement. Groups commonly share best practices as a solution to solving many academic concerns that students may have. Strategies for school improvement must focus on the particular needs of students (http://www.ed.gov/pubs/turning/strategy.html) and support of school's leadership team. 


\section{COMMON ORGANIZATIONAL STRUCTURE}

Working in small groups, faculty set behavior expectations, length of each agenda-driven meeting, role and responsibilities of each participant and group members remain in the same group during the entire academic year. By utilizing an agenda-driven schedule for meetings, groups will meet 45 to 60 minutes once a week before school, during lunch or after school. The group's focus in general is about discussing how to improve students' skills in reading math and English, science and social studies. The need to improve student achievement is based on the collection of available formative and summative data. Using technology and input from group members, groups are able to monitor the progress of students weekly as whole or interdisciplinary groups. On the agenda, groups will include pertinent items for discussion and expected outcomes at the end of each meeting plus identify steps to be discussed at the next meeting. All group members are encouraged to contribute agenda items for the next discussion. It is the overall goal of all groups to sustain momentum with frequent meetings to discuss classroom practices to ensure that students are making positive progress in their classes. Each faculty-study group keeps the larger school's leadership team informed of their activities and progress (http//www.montgomeryschoolsmd.org).

\section{THE USE OF DATA}

Faculty-study groups determine what data is available for review. Each group secures the needed data as soon as possible and format the data in a read-friendly manner. Using segmentation of data, each group then decides what does the data mean and what are the data trends for grade level performance and individual student performance. Study groups value the availability and use of data for supporting school improvement.

During meetings, faculty study groups determine what should be done with the data; compose reports on data early, length of time during meetings, how long group members need to spend reviewing data, and to take into account demographic information such as gender, race, and eligibility for FARMS and language spoken at home. Most importantly, each study group looks at students' performance individually by name and specific skills needed to be improved upon before developing an action plan for improvement (Fox, 2004).

\section{HOW TO PROCEED AS A GROUP}

After collecting and analyzing data information, faculty-study groups communicate data finding to stake holders i.e. other faculty, individual students who need to know, parents and the school leadership team. From the findings for example, faculty-study groups may say it appears that students have a concern in comprehension in the content area of a specific discipline. After that, an agreeing faculty group would establish realistic goals to attempt to meet the individual needs of students in the area of comprehension. Whatever, the specific needs maybe be, per identified student, faculty study groups may re-teach a skill using different methods for instruction, offer extended time to students, use appropriate grade level research-based interventions such as: Reading 180, Accelerated Reader, Compass/Odyssey, Fastt Math, Hooked on Phonic, Study Island, Lexia and/or Symphony Math. Some study groups may observe an expert during professional development workshops/seminars that may have more knowledge about comprehension skills in the specific content area. Faculty study groups may implement a variety of strategies that address the concern, observe a model faculty member in other classes, schools or counties, seek coaching for specific strengths and needs in the targeted areas, examine relevant research projects focused on a specific area of concern and then look at up-to-date data from the students in question to see if students have improved their performance. Many interventions and support to students today, beyond an individual teacher, are generally computer-based. With consistent monitoring strategies in place using technology, faculty-study groups are able to see how students are performing weekly, bimonthly, quarterly and at the end of each semester.

\section{STUDY GROUPS AND CASE AT A GLANCE REVIEW}

The key responsibility of faculty-study groups is to take the initiative in improving the performance of their students using a collaborative approach. Casing at a glance in two middle schools environments in a large school district on the east cost of the United States of America, faculty-study groups had the belief that they could improve their school from within by identifying the root causes of students' performance and using best practices to overcome the concern. The two schools observed were composed of a combined number of 1300 students, and 32 
school improvement team members. A total of thirty to forty students in each school, performed below standard on state assessment tests in 2005 thru 2007. Faculty had the idea at end that as a group they could improve their own school from within. Faculty-study groups in these two schools worked before school, lunch time, after school and during the advisory period with identified students needing help during four days a week and the results to believable. As a starter, students were shown their own assessment data, and agreed to participate in the extra support efforts that were afforded them. Approximately two hours a day for four days a week made a difference based on reports and opinions from faculty. With a constant practice of rigor and challenging instructional activities for students, finding ways to improve their own knowledge and skills to deliver high quality instruction and conducting targeted mini-professional staff development activities related to the needs of students, faculty members were convinced to have made the difference in positive student learning. During June 2008, the two middle schools faculty groups learned from their administrative team that their school made AYP (state assessments) and students showed a great deal of progress on unit assessments. The two schools plan to continue with the facultystudy group practices, because of the observed school improvement.

Among the participating schools in the case at a glance, faculty-study groups felt that working together with the school leadership team for the common cause of improving the academic environment of the school made the difference. Using the Malcolm Baldrige model, continues to give faculty-study groups the opportunity to see and utilize a framework that has creditability in guiding schools toward improvement. Faculty study groups stress emphasis on knowing students and knowing students' academic and social needs are all key factors in helping students to improve their academic skills and knowledge. The emphasis of knowing your students and knowing what their needs can help groups to target appropriate instructional support to meet students' individual needs. Using this model help groups to establish a leadership system, participate in courageous conversations and articulate priority goals for subgroups and prepare an action plan based on the needs of students. Faculty study groups review the process management for strategic goals setting and planning for improving students' performance. Faculty study groups continue to look at measurements, analysis and knowledge management using formative, summative assessment and staff input. Staying in close communication with the school leadership team, faculty study groups avoid duplicating efforts. Data sources used for school improvement to promote student achievement comes from such systems a data warehouse, local in-school data banks, staff generated data, academic data, non-academic data such surveys and questionnaires and feedback in the form of pluses and deltas

\section{MALCOLM BALDRIDGE FRAMEWORK}

As data is reviewed, each study group should develop its own strategic action plan. The action plan should be goal-driven based on the identified need(s). If there are six faculty-study groups in the school, there should be six action plans. All action plans should be made public to the entire school. The plans could be in the faculty lounge, library, school instruction leadership team room and other meeting rooms. According to the Malcolm Baldrige framework, a typical action plan could contain the following information in a spread sheet format using excel: groups' specific goal(s) articulated, action steps/objectives process timeline, person responsible, resources needed, monitoring tool or data points (formative, summative), monitoring date and by whom, and results/next steps include evaluation of processes for effectiveness and efficiency. This format gives faculty-study groups a consistent way of recording questions of who, what, when, why and how.

The action plans should be revisited monthly to see if compliance areas are in order. If adjustments are needs, the group should collectively revise the document where applicable. The ownership of the group is important as the group formally evaluates the intended progress of their own work. From this evaluation, the group will be able to determine if the intended goals were met (http//www.montgomeryschoolsmd.org)

\section{SUPPORTING SCHOOL IMPROVEMENT EFFORTS}

Faculty-study groups continue to seek the support of school's leadership team. Faculty-study groups in two middle schools placed emphasis of support in the implementation of curricular and innovative approaches to improved instruction. While its seems obvious, many schools pay inadequate attention and time on providing high quality classroom instruction and using resources in many ways that improve what happens between the teachers and students in the classroom (http://www.ed.gov/pubs/turning/strategy.html). These study groups continue to share 
best practices with faculty and give continuous support for improved programs. In order to stay on target, these groups frequently monitor the instructional need of students through research-based interventions, appropriate accommodations and resources and discuss as a group is there a change in students' performance in a positive matter.

As the faculty-study groups continue their work, the groups believe that they are making a difference in the effort to support school improvement. Groups stay focused on their intended goals, gain new and improved knowledge and skills to meet the academic and social need of students, use the correct curriculum materials and share best practices to provide high quality instructional services to all students. By using new and improve ideas for higher student achievement, faculty study groups sometimes modify instructional delivery services and utilize technology as a tool improve the management process in each group plus monitor and assess students' performance.

\section{USE OF AN ACTION PLAN}

An action plan serves as a guide for faculty-study groups and members of the staff/faculty to follow when determining priorities goals for school improvement. In a typical school environment, faculty-study groups develop an action plan and time line for improving reading, math, English, science and social studies based on best practices. Improving student attendance or student behavior; a plan that gives students support through interventions that are research-based and/or a plan that encourages more parent involvement may be also a common focus or helps set priority goals for some schools.

The action plan written by faculty-study groups is usually in excel format. The plan is written in measurable goals; states how the goals will be met; identify the person(s) responsible for executing the goals; state needed resources (human and non-human); must show evidence of implementation; type of strategic monitoring plan by date and by whom; give results including evaluation of processes, effectiveness and efficiency. At the end of the plan, faculty-study groups will give reasonable next steps to address issues based on the outcomes of their work for school and student improvement.

The action plan should be made public in the faculty resource room, library, leadership team document center, and relevant document must be available for review by all stakeholders. The study groups should revisit the contents of the action plan monthly for compliance based on the groups stated intentions. In essence, the plan needs to be monitored and evaluated to see if the targets were met.

At the beginning of the academic school year, faculty-study group members pay a lot of attention to summative assessment information related the outcome of state test results.

\section{LOCATION OF SOME EARLY STUDY GROUPS}

In order to promote ways to support school improvement efforts, faculty-study groups are taking the initiative to make it happen in many school districts. Faculty-study groups can be found actively engaging in performing leadership positions in improving their schools in Decatur, Sandersville Marietta, Georgia, Corpus Christi, Round Rock, Texas; Boyle County, Kentucky, Holtville, National City, San Diego, California, and Greeley, Colorado. In participating states, time may be set aside for study groups to meet one Wednesday a month, daily 90 minute planning period, one hour week, meet every other week for one hour, or meet two hours every Wednesday. There are many time configurations when groups meet. In each case parents, the Board of Education and school leaders have deemed that faculty-study groups have a presence of value and importance to school improvement and that is why this effort is supported. In essence, faculty-study groups take ownership for the improvement of students' performance. It is the groups' belief that they are capable through their own self-empowerment to make a significant difference in school improvement. Faculty-study groups create and conduct their interdisciplinary or department professional development activities. This collaborative effort by faculty helps increase faculty's skills and knowledge. This further helps faculty study groups to have the potential of creating a broad-based way of systemic change and academic improvement in the school (http://www.nsdc. org/library/publications/jsd/Murphy 183.cfm) 


\section{LEADERSHIP TEAMS SUPPORT STUDY GROUPS}

With the support of a transformational administration in the school, faculty-study groups can become instructional experts and managers of their own teaching and learning ability to improve student achievement. The transformation leadership and administration in public schools gives new freedom in the classroom which encourages teachers to incorporate personal vision of educational excellence in a supportive superstructure, all in the best interest of the students in the school. Since the theorist James MacGregor Burns's conception of transformation leadership, there has been an effort to induce followers to be motivated and encouraged to be both followers as well as leaders (http://www.thirdlayer.org/sw/papers/transform.html). The leader according to Burns is not the one who merely wield power, but appealing to the values of the followers. Burns insists that for leader have the greatest impact on the "led" they must motivate followers to action by appealing to shared values and by satisfying the higher order needs of the led, such as their aspirations and expectations. In a school environment where the leader embraces faculty-study groups to led, that environment is far more productive. Today's networked, interdependent, culturally diverse organization requires transformation leadership to bring out... in followers... their creativity imagination and best efforts. People such as faculty-study groups who think on their feet, are creative, come up with the best solutions, don't need to closely supervised and do what is necessary just because it is the right thing to do to ensure school improvement and student success. Faculty can utilized best practices based on research and test performance with their own groups using a rubric. Using applicable materials and language from the "Skillful Teacher" (Saphier, Haley-Speca, Gower, 2008) faculty-groups could develop and use a common language for management, instruction, motivation and curriculum. This common language that is research-based could become an integral part of the schools' culture. When faculty members are encouraged to analyze the learning that is taking place in their classroom, this empowers faculty to take charge of their own success. As faculty engages in their purposeful learning, they are able to develop their own professional learning communities and focus on meeting the needs of their students (Murphy, Lick, 1998).

\section{ESTABLISHING A FACULTY-STUDY GROUP}

The first step in establishing faculty-study group is to publicly inquire among faculty to find out who is interested in joining the study group. The articulating of the reason/need, purpose and process guidelines must be clearly defined for the study groups. There is a need to share faculty-study group success models with potential participants in the groups so that benefits may be considered. The emerging leader for the group must make a compelling argument that the faculty-study could impact student achievement in the positive. Too many faculty members may feel that this just another task or responsibility that they don't need.

\section{BENEFITS OF STUDY GROUPS}

Faculty-study group are able and capable of perfecting positive change in the school's culture, because faculty are improving their own teaching and learning through data-driven decision making (Murphy, 1998). It is the belief that the benefits of the faculty-study group allows participants in the group the freedom and flexibility to explicate, create and evaluate specific practices that will address the needs of their students through collaborative efforts. As faculty work together there is a public way of unity among members of the group who share new and improved practices to offer students "real world and challenging experiences" to expand their academic, social and cultural awareness skills.

Faculty members could learn about other successful study groups in their efforts to improve their school with the support and encouragement of the school's leadership. Most study groups are composed of five to six individuals in the same subject area or across disciplines. The groups meet once or twice a week for forty-five to sixty minutes. Group members may meet before school, at lunch or after school with an agenda-driven purpose and each member of the group will have a defined role and responsibility. The study groups are often composed of individuals who want to investigate specific student needs that have been identified through data records. With the review of the data, faculty are able to see students need for example in reading, math and/or English.

Meeting on a regular basis and examining students' performance faculty members in the group can keep pace with ongoing learning and put into place a strategically planned support system. According to Murphy 1998, 
working together, faculty can be innovative and creative in meeting the individual needs of group members. From the research, it is strongly recommended that group members stay together for a year and groups should establish a regular meeting time with an agenda. When groups meet for the first time, it is essential that the group collectively establish expected behaviors of the participants. For example, group members should agree on a beginning and ending time for meetings, respect each others' opinion and bring to the meeting needed resources and materials as promised. Agree to review data frequently to determine needs for the group.

The most critical area is for faculty-study groups to focus on the appropriate curriculum and instructional delivery process and to be afforded the time for group meetings. The curriculum should be challenging and rigorous in content and implementation. Faculty-study groups need to know the curriculum and how to teach it creative and meaningful ways to ensure student success (Loucks-Horsley, 1998). The impact of instruction and support of professional development should make a positive difference in student learning and the desire to learn.

Another way of valuing the faculty-study groups concept is to look at how these groups support the implementation of curricular and instructional innovation, integrate and give coherence to a school's instructional practice and programs, target a school wide instructional need for especially for subgroups, and monitor the impact of instructional changes on students. In order to learn more about the four functions broached about, it is necessary for groups to address information in the content area such as skills, knowledge, resources for curriculum, best practices for instructional strategies, look at curriculum design, use technology as tool for instruction and management, customize instruction specifically for the needs of students, monitor all practices and evaluate/assess these practices.

Faculty-study groups could accomplished more if they were participate in professional learning community activities, visit their colleagues classroom, participate in coplanning, coteaching and coassessment of progress. Faculty-study groups need to (1) keep a group log of meetings held (2) encourage individual members of the group to keep personal reflection log. Such personal reflection could include: Date, who was at the meeting, what was accomplished, was the meeting purposeful, for the future meeting what will I need, what am learning from best practices, think about how I was disappointed, and how are my students benefitting from this experience?

Annually, schools are able to examine their students' performance per subgroup across the nation. This electronic data from the state department gives schools a view of test data for the academic year. Faculty and staff members continue to ask the questions, how do we improve our students' performance? Some additional questions are asked by faculty/staff: is our instruction framework aligned with the state content standards, do we know where our students are in relation the standards, do we have a monitoring system in place to follow the progress of each student individually using classroom data, how do we examine students' work and monitor data to guide the instructional process and implement appropriate research-based interventions, do our faculty members need to build capacity in their work, do special education faculty need to know and be able to do and who can we give more support to the special education faculty, and/or does our school have in place the planning and scheduled time and expectations for teams or groups to collaboratively check classroom data and students' work individually (http://mdk12.org/data/sept/improve.asp?graph=MSA*SID=1RE\&SUB=Rading\&perf=Hi)

Group of faculty members from two middle schools located in the suburbs in a large state on the east coast of the United States who were members of the larger school instructional leadership team, decided to drill down their thinking to forming a faculty-study group to attempt to address the needs of their students. This faculty-study group had a belief that the school could improve from within. The faculty-study groups were established with a goal-focus on practical approaches to create conditions for continuous systemic change for academic improvement for students who perform below standard as measured on state assessment test and those students who show low performance on formative and other summative assessment (http//www.montgomeryschoolsmd.org).

The success record of study group is influence by the support received from the leadership of the school. When there is transformational leadership in schools, there is a practice that moves followers into the transformational style. There is shared trust between the leader and the faculty. The leader inspires and motivates followers with challenges and meaning to engaging in shared goals and undertakings. The transformational leadership style appeal to what is right and needs to be done provides the impetus for all to move forward. With 
intellectual stimulation by the leader, faculty study group types are able to implement the "big picture" of setting goals and objectives in meeting the individual needs of students. A supportive leader of the faculty-study group efforts, help groups to fulfill their individual needs for self-actualization, self-fulfillment and self-worth in making a difference in the school (http//www.montgomeryschoolsmd.org).

\section{PROFESSIONAL DEVELOPMENT ACTIVITIES}

Faculty-study groups perform many functions in schools today. These groups sometimes will conduct appropriate and focused professional development training for other faculty-study group. As a collaborative group, some faculty study groups develop their own tool kit as an artifact for others to follow. With the use of research information, these groups discuss success stories about other faculty-study groups. Believing in the strength of faculty, many study groups utilize the expertise of peers at the school site. The key to school improvement by improving instruction, faculty-study groups collaboratively develop lesson plans that will be implemented in the classroom and discuss as a group how to measure student success by giving some specific examples.

\section{ENHANCING CURRICULUM}

Through a collaborative approach, faculty study groups align local curriculum with state standards in a manner that is usually friendly. Groups seek current plus relevant materials and resources for all courses taught in their perspective building. It is common to see students' work and projects displayed as models for others to see. Faculty-study groups have the attitude of keeping curriculum interesting and exciting for student learning. These groups create their own instructional guides and use company designed guides or manuals. With the belief of worth of groups, faculty will take the lead in conducting needed training, workshops, seminar to improve their own instructional knowledge and the delivery system. Members of faculty-study group present at conferences, professional development activities, workshop and seminars. In schools, there is a tremendous amount of action research to capture, with appropriate permission, some faculty-study groups participate in recording, publishing experience and sharing again success stories as they interact with other study groups and the school improvement leadership team.

\section{GOALS OF FACULTY-STUDY GROUPS}

These are some of the common goals held by faculty-study group: demonstrate the need to think like a group and the group's overall goals is to "improve student achievement," take time to support members of the group, share group leadership experiences and utilize the strength of each faculty, show discipline as a team and invite others to join the groups' effort during September/June and to keep the school leadership team/administration informed about group progress.

\section{A SHARED EXPERIENCE}

Leadership practices within the faculty-study group should be shared among the members. Each month, most faculty-study groups rotate the leadership group experience among the 5 to 6 members. It is the effort of the group to work on ensuring that each leader in the group is comfortable with data related maters, effective communication, relationship building skills and how to handle challenging issues. Using a collaborative effort, the group helps the new leader to prepare appropriate and timely agendas for meetings, pertinent matters and communicating with others who are not participants in the groups and to work with other to share the responsibilities of the study group.

\section{SOME CHALLENGES FACED BY FACULTY-STUDY GROUP}

The participating faculty-study groups believe that their biggest challenges are as follows: finding adequate or some professional development funds to pay for faculty stipends for before and after school time. Quality time spent with student appears to work, because of the down swing of the economy, faculty-study groups seek some level of compensation for their time. Second challenge is have the principal/leadership team to schedule common planning time, half-day or school hours to meet more frequently for shorter periods of time for agenda 
discussion items. Third, to incorporate study groups' time during regular professional development activities or school improvement leadership team planning time so that each faculty-study group may conduct their official business (Palmer, 1997).

\section{WORTHWHILE OF THE GROUP}

Based on a ten year study of research, according to (McLaughlin, 1993) effective schools have collaborative professional learning communities with faculty-study groups have made a positive impact on schools. Effective departments within schools, without exception, that school or department has been a part of collaborative professional learning communities continues to impact schools that faculty study groups are worthwhile in the improvement of student achievement.

\section{COMMON QUESTION ASKED AND ANSWER GIVEN}

These are some typical questions asked about faculty study groups. Will faculty-study group improve or increase student achievement? Will the configuration or composition of faculty-study group increase student achievement? Will faculty-study group make an impact on student achievement? A concluding answer suggest that what takes place in the classroom makes the difference as to how students make progress or achieve needed skills and knowledge (Murphy, Lick, 2001).

\section{SUMMARY}

After communicating with faculty-study groups from two middle schools, these were frequent statements made regarding their feelings of success in making a difference in school improvement as pluses and deltas:

- $\quad$ Acquired exceptional sharing and reviewing of school data, frequency of meetings, outside input and support, recommendation for improvement/enhancement, directions were clear, had a deeper reflection on instruction.

- Gained more access to school data and understood how to analyze the data, having a better and more complete perspective on school expectations, being able to track student data over the years, input from all departments, knowing the students more personally, expectations that rigor applies to all students.

- Obtained and utilized feedback from other teachers, sharing best practices, agenda-driven meeting, equitable engagement of group members, balance of school data vs central administration data bank.

- Observed a positive attitude of group members, being able to provide suggestions for greater student success, comfort level among group members, ideas generated by individual groups, celebrate success as often as possible for school improvement, help from specific group members.

- $\quad$ Appreciated the collaboration in groups, time limit was honored, open and honest discussions, materials needed were available, getting positive feedback, frequency and the amount of time on task/agenda.

- $\quad$ Observed the area of deltas such as: a few faculty group members said that they felt that preparing data for meetings took too long, would like to know more about other faculty groups and how they function and make progress.

From the pluses and deltas, this study suggests that these faculty-study groups felt that their efforts made a positive difference in school improvement.

\section{AUTHOR INFORMATION}

Ann Hilliard is an assistant professor in the School of Education, Department of Educational Studies and Leadership at Bowie State University. She received her Doctorate of Education degree in Higher Education and support fields in International Education and Education Administration from George Washington University for her dissertation on "An Investigation of Selected Forces and Events that Contributed to the Growth and Development of Trinity College, Washington, D. C. from 1897 to 1982." She also holds M.S. degrees from The Johns Hopkins University at Baltimore in Supervision and Administration, Trinity University in American History, a Certificate from Harvard University in Consulting and a B.S. degree in Business from Elizabeth City State University. She has 
served as Director for Graduate Studies at Sojourner-Douglass College and Director for the Scholars' Program/Deputy Director for Science, Engineer and Mathematics (grant funded programs) at Bowie State University.

Hilliard is interested in research topics related to: faculty-study groups support school improvement efforts, a contemporary look at transformational leadership, data-driven decision making, school assessment, role of leaders in school improvement, relationship building and effective interventions, and networking for success. She has received many awards and certificates in leadership, instruction and best practices for test taking skills. With the appropriate skills, knowledge, attitude plus determination by faculty and staff, Hilliard believes that schools can improve from within.

For over twelve years, Hilliard has presented papers in the U.S. and aboard. Presentations were made on these research topics: Best Practices for Teaching Reading to Middle School Students -Seoul, Korea, 1996; Best Practices for School Management and Test Preparation - U.S. Virgin Islands, 1998; Be A Risk Taker: Step Forward and Lead - University of Maryland/College Park, 2002; Best Practices for Retention of Students, Proposal Writing Workshop Honors College/Scholars Program - Bowie State University, 2002; Mentoring Students in Graduate School - Sojourner-Douglass College, 2003; Networking Marketing - University of Maryland/College Park, 2003; Teaching as a Profession - Sojourner-Douglass, 2003; Cultivating Inclusion Cultures - Baltimore, 2004; Social Action Research Workshop; Effective Communication for School Improvement, 2008, and DataDriven Decision Making, Effective Coaching/Facilitation Workshops for Montgomery County Public Schools, 2008. Hilliard is scheduled to present a workshop on Relationship Building for Staff and Students in Secondary Schools George Mason University, 2009. Seeks presented paper for publication: Faculty-Study Groups Support School Improvement Efforts - Clute Institute in Littleton, Colorado, 2008. In the area of student research, Hilliard serves as dissertation chairperson and a member of various committees in the School of Education - Department of Educational Studies and Leadership at Bowie State University.

\section{REFERENCES}

1. Fox, D. (2004, June). Guiding instruction through assessment. Leadership: Magazine of the Association of California School Administrators.

2. $\quad$ http://www.ed.gov/pubs/turning/strategy.html

3. $\quad$ http://www.nsdc.org/library/publications/jsd/Murphy 183.cfm

4. $\quad$ http://www.thirdlayer.org/sw/papers/transform.html

5. http//www.montgomeryschoolsmd.org

6. $\quad$ http://mdk12.org/data/sept/improve.asp?graph=MSA*SID=1RE\&SUB=Rading\&perf=Hi

7. Loucks-Horsley, S. (1998). Ideas that work: Mathematics professional development. The Eisenhower National Clearinghouse for Mathematics and Science Education. Washington, D.C.

8. McLaughlin, M.W. (1993), What matters most in teachers' workplace context? U. S. Department of Education, Office of Educational Research and Improvement, Washington, D. C.

9. Murphy, C. (1995). Finding time for faculties to study together. Journal of Staff Development. 18 (3), 2932.

10. Murphy, C. \& Lick, D. (1998). Whole-faculty study groups: A powerful way to change schools and enhance learning. Thousand Oaks, CA: Corwin Press.

11. Palmer, P. 1998). The courage to teach: Exploring the inner landscape of a teacher's life. San Francisco, CA: Jossey-Bass.

12. Spahier, J., and Haley, M. Activator: Activity Structures to Engage Student Thinking Before Instruction. Acton, Mass.: Research for Better Teaching, 1993. 


\section{NOTES}

